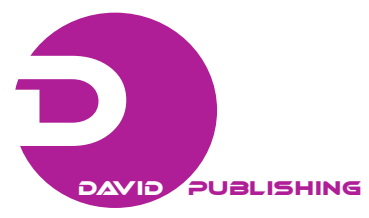

\title{
Design of Monolithic Concrete Ground Floors
}

\author{
Alexandros D. Bantias, Ioannis A. Tegos, Theodoros A. Chrysanidis and Asimina M. Athanatopoulou \\ Department of Civil Engineering, School of Engineering, Aristotle University of Thessaloniki, Thessaloniki 54124, Greece
}

\begin{abstract}
It is known that the slabs on soil constitute one of the most difficult types of structures despite their apparent simplicity. The objective of this paper is to give a general survey of the design of ground supported slabs with the interposition of a suitable subbase. A solution is proposed with the following characteristics: (1) complete suppression of joints; (2) conventional reinforcement with meshes in the upper and lower fiber of the slab in order to confront and distribute cracking that is caused by hindrance of free contractions and expansions; (3) effective confrontation of problems of bulging. The proposal is in effect on one hand for industrial floorings and on the other hand for concrete pavings with large durability requirement.
\end{abstract}

Key words: Ground slabs, restraints, durability, jointless, fatigue.

\section{Introduction}

The design and construction of concrete slabs on soil constitutes a difficult task despite their apparent simplicity. It is not accidental that there are still no recommendations on their proper construction. As main cause of their failure, someone could mention the restraints expressed either as differential settlements or, mainly, as hindrance of contractions and expansions. For the confrontation of restraints, solution can be given by the joints (contraction joints, construction joints, isolation joints, etc.). Because of the big density of joints, the slabs are manufactured as non-reinforced or fiber reinforced with small percentages of steel fibers because of the unfavorable influence of big percentages in workability of fiber reinforced concrete. Also, at the joint locations, the suitable placement of dowels is required to guarantee the collaboration of neighboring segments.

Joints, along with the absence of conventional reinforcements, constitute the Achilles' heel of these structures since they require maintenance, they are prone to local failures and for the slabs which are manufactured in the countryside, they constitute the entries of rain waters and of melted, via salt, ice.

Corresponding author: Theodoros A. Chrysanidis, Dr., research fields: concrete design and earthquake engineering. E-mail: theodoros_gr@yahoo.com.
Failure of joints can happen also because of the phenomenon of pumping, which can lead to extensive cracking and detachment of segments of concrete from the surface of slab at the region of joint.

There is no correlation between ground slabs and those supported on beams. A notable fact, indicative of our ignorance concerning this issue, is that there are no precise instructions referring to ground slabs. Furthermore, the multiple applications of ground slabs force engineers to research thoroughly the international bibliography for defining specific rules concerning their construction and design.

The strains these slabs are subjected to are derived from point loads, uniformly distributed loads and restraints due to deformation hindrance. The causes of restraints are the expansions and contractions that concrete undergoes due to its drying, temperature changes, temperature difference between the top and bottom side of the slab and the differential settlements due to local subsoil deformation.

As in the case of conventional slabs, the main purpose is to calculate the thickness and reinforcement. Slab thickness is supposed to be determined by the flexural, shear and puncture loads. As far as the reinforcement is concerned, the ground slabs case is considerably different to the conventional slabs case. Traditionally, ground slabs in real life are weakly 
reinforced using grids on the top and bottom of slabs which operate as surface reinforcement rather than bearing. Today, these slabs are either unreinforced, therefore operating at stage I (uncracked concrete), or reinforced with steel fiber (percentage of reinforcing steel $25-30 \mathrm{~kg} / \mathrm{m}^{3}$ ). By using such low reinforcement, it is intended to accommodate two basic requirements: concrete workability and load bearing mechanism activation by the two sides of the slab. Steel fiber reinforcement imparts ductility to concrete, so bottom side failure activates the top side and that enables us to use the yield line theory. Certainly, steel fiber reinforcement does not affect considerably the flexural capacity of the slab, compared to the unreinforced concrete case.

Regarding the restraints, joints is the "remedy" used for strain relief. Occasionally, in order to reduce the slab thickness, dowels are used to connect the adjacent parts of the slab which is divided in rectangular parts of size $5 \mathrm{~m} \times 5 \mathrm{~m}$. However, it is no exaggeration to say that sometimes the "remedy" proves to be worse than the disease that it is supposed to cure, more precisely, the profuse cracking of the slab. Currently, it is known that we are on the verge of releasing ourselves from the joints. Many large area buildings and long-span bridges are constructed jointless. According to the beliefs of the present article's supervisor, who has a long experience in analyzing jointless solutions for bridges and buildings, it is time to apply this philosophy in ground slabs, since joints, as mentioned before, cause more troubles than restraints do.

The abolition of joints was on the table of discussion, the period when railways were constructed with expansion joints in every $30 \mathrm{~m}$, due to intensive phenomena concerning thermal expansions and contractions. However, it was noticed that the rails displacements due to thermal changes were much lower than expected and as a result, joints were connected by welding. In today's railways, welded connections are used and in that way deformations are confronted.

The study of the temperature changes' influence on the length-deformation relationship of several elements and the abolition of joints in building and bridge construction, is addressed in many scientific papers. However, bridges outpace buildings in current bibliography.

Both the construction and the abolition of expansion and contraction joints in buildings include disadvantages which have to be taken into account during their design, operation and maintenance. More specifically, the existence of joints increases the construction cost and their maintenance implies many difficulties. Moreover, the application of joints increases the possibility of moisture appearance and disrupts the building's uniformity (e.g., dual walls). In contrast, the abolition of joints intensifies strains due to restraints and as a result more reinforcement is required in areas where tensile forces are more likely to take place. For that reason, reinforcement is used on the top and bottom side of the slab. Additionally, in jointless constructions, it is essential that cracking control has to be performed, since constrained and imposed deformations due to restraints (temperature, creep, shrinkage, settlements) cause high stresses to indeterminate systems. In conclusion, a significant disadvantage of joints' abolition is the problematic application of precast methods, because of the difficulties arising in assembling and transporting precast members.

The objective of this paper is to give a general survey of the design of ground supported slabs with the interposition of a suitable subbase. Despite the fact that the dimensioning of these slabs is seemingly easy, there are many factors that affect their behavior or functionality that should be taken into consideration. A solution is proposed with the following characteristics: (1) complete suppression of joints; (2) conventional reinforcement with meshes in the upper and lower fiber of the slab in order to confront and distribute cracking that is caused by hindrance of free 
contractions and expansions; (3) effective confrontation of problems of bulging. The proposal is in effect on one hand for industrial floorings and on the other hand for concrete pavings with large durability requirement.

\section{The Main Disadvantages of Current Construction Methods}

The seeming simplicity of dowels' application disorients us from their real behavior. For example, if dowels are not exactly perpendicular to the joint, they will hinder contraction of the slab, causing or contributing to cracking. Corrosion is another issue that impedes free movement of dowels in and out of the slab and can also cause spalling.

It is of outmost importance that doweled joints should be able to open and close as concrete expands and contracts. For that reason, dowels should be slippery and smooth in order to slide in and out of the concrete without resistance. Smoothness alone does not guarantee free movement of the joints, so a bond-breaker is also needed at the dowel surface. In order to improve dowel performance, grease, mortar-tight sleeve or noncorrosive sleeve could be used.

Conventional round dowels must be parallel with each other and with the sides and surface of the slab. Dowels which are not aligned have to bend as the joint opens. This can generate immense tensile stresses in the concrete. As a result, cracking and reduction in load carrying capacity occur. Proper positioning of bars could be achieved by using prefabricated alignment cages but even with these, the problem persists. Fortunately, misalignment is usually not obvious.

Whatever provision is made, several issues still come up. For example, if the top or bottom of the bar is heavily greased, one slab must deflect by an amount equal to the grease thickness before load is transferred to the adjacent slab. High stresses can occur long before the load is transferred. A similar problem may come up if there is any space between the bar and the sleeve. Additionally, if corrosion occurs on the bars and sleeves or mortar enters the sleeve, dowel movement will be hindered.

Even though dowels and tie-bars may be perfectly placed, movements perpendicular to the bars and parallel to the joints are restrained, causing notable stresses which lead to cracking or failure. However, these stresses were not included in the analysis and design of the slab.

Usually, large floor slabs or pavements are dealt with by using the long-strip method. More specifically, lanes are placed separately each day and the intervals are filled later. When placing the lanes, workers saw cut transverse contraction joints the same night or the next day. After one or two days, cracks occur below the saw cuts and thus the joints open. The main problem of this method takes place several days after the filling of the aforementioned intervals. The new concrete tries to contract but the bars in the longitudinal joints resist. Certainly, the new concrete has not developed its full strength and cannot withstand the tensile forces applied to it. Consequently, cracks are formed.

Also most designers usually ignore the horizontal shear force occurring parallel to the joint at about the end of the bars. It is also essential to say that slabs, when put into service, can be already cracked or highly stressed. Especially at the intersection of transverse and longitudinal joints, stresses accumulate and thus cause corner cracking, as shown in Fig. $1[1,2]$.

\section{Description of a Jointless Solution}

\subsection{Floor Loadings}

The loads, slabs-on-ground are subjected to, fall into two categories: Gravity loads and restraints. The first category includes forklift and heavy wheeled vehicle traffic, block stacked pallet loads, racking loads, loads from bearing masonry or partition walls and loads from fixed machinery and equipment. The 


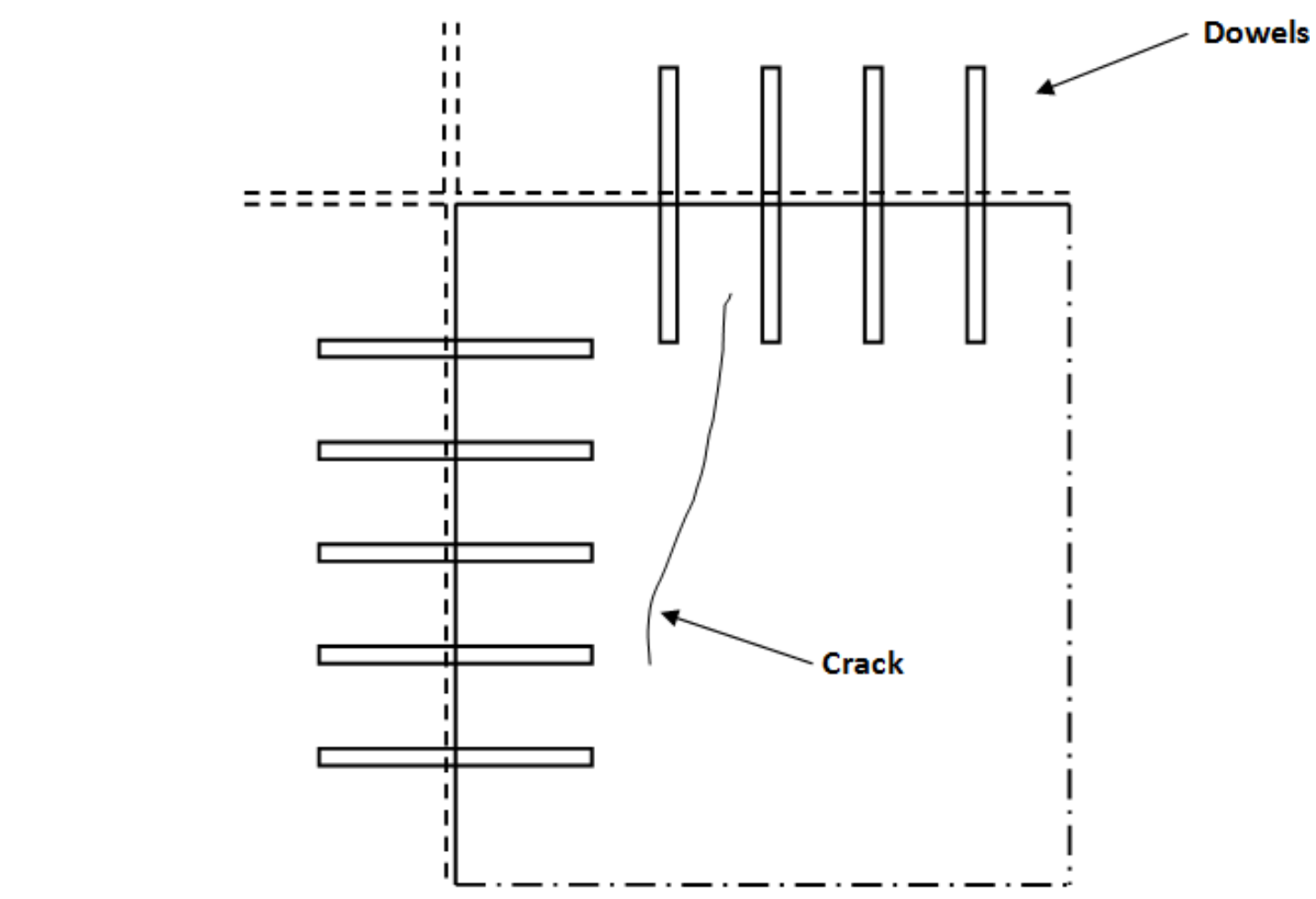

Fig. 1 Cracking caused by bars at the corner of a slab.

second category includes differential settlements, uniform temperature changes $t_{s}$, temperature difference between the top and bottom side of the slab $\Delta t$, concrete drying and concrete deformations.

Reliable load carrying capacity is of utmost importance in ground slabs design. Self-weights and service loads are determined by codes where point loads (derived from forklifts) are given. These point loads fall into six different categories. As far as the wheel loads and the dynamic amplification factor of machinery equipment are concerned, they have to be estimated with the help of the owner's contribution as well.

All the above apply both to the self-weight loads and service loads of racking systems, too. Attention should be paid to manufacturer's details. Furthermore, as for the racking systems, measures must be taken against their overturn caused by horizontal seismic load applied to the center of gravity of stored material. Regarding the racking systems and forklifts, it is critical for the stress calculation of ground slabs to consider their total load. Concerning the truck traffic loads, they have to be determined with the help of the owner's contribution, likewise forklift loads.

Regarding indoor ground slabs, uniform temperature changes $t_{s}$ equal to $\pm 25{ }^{\circ} \mathrm{C}$ according to EC-1 must be considered. Also, in order to estimate the deformations due to concrete drying, primarily in the incidence of large glass facades, it is possible even for indoor conditions that an equivalent temperature greater than $35{ }^{\circ} \mathrm{C}$ is required. In the case of indoor slabs, application of temperature gradient is not required, provided that: (1) the placement of the slab is accomplished after the construction of the roof and exterior walls; (2) the room is already heated.

For the sake of simplicity, live loads and restraints are determined using a safety factor equal to $\gamma_{Q}=1.5$ and $\gamma_{Q}=1$, respectively. The application of $\psi$ combination factors would give the illusion of computational accuracy but due to the multiple elements that influence the ground slab behavior, such an effort would be pointless. This fact characterizes as well the concrete modulus of elasticity estimation. For the design and construction of ground slabs, the 
modulus of elasticity of concrete is considered equal to $E_{c}=30,000 \mathrm{~N} / \mathrm{mm}^{2}$, which is quite accurate if it is referred to usual classes of concrete (C25/30, C30/37). The thermal expansion coefficient $\alpha_{t}$ for concrete and steel is assumed to be equal to $1.0 \times 10^{-5} \mathrm{~K}^{-1}$ according to EC2 [3-7].

\subsection{Restraints Consequences}

\subsubsection{Uniform Temperature Changes}

Friction between the slab and the soil generates compressive stresses at the bottom surface of the slab with increasing temperature and tensile stresses with decreasing temperature, as indicated in Fig. 2. Long span slabs exhibit greater sensitivity.

A jointless slab lying on graded crushed aggregates, despite the presence of a slip membrane that hinders its movements, forms cracks under a temperature reduction of $20{ }^{\circ} \mathrm{C}$. Stresses resulting due to the above temperature reduction are given by the relation:

$$
\sigma_{t}=\alpha_{t} \cdot t_{s} \cdot E_{c t}=1 \cdot 10^{-5} \cdot 20 \cdot \frac{30,000}{2}=3 \mathrm{~N} / \mathrm{mm}^{2}=f_{c t m}
$$

where,

$E_{c t}=0.5 \cdot E_{c}\left(E_{c t}=\right.$ modulus of elasticity under tensile forces);

\section{$f_{c t m}=2.9 \mathrm{~N} / \mathrm{mm}^{2}$ for $\mathrm{C} 30 / 37$.}

The above concrete flexural strength $f_{c t m}$ is not sufficient to prevent cracking. It should be noted that expansion and contraction of concrete is an

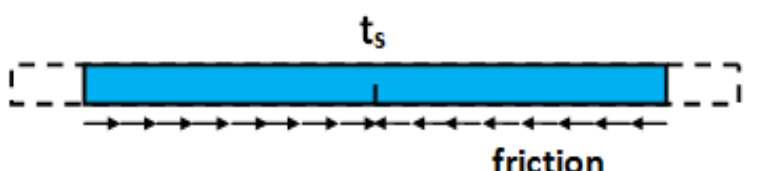

friction

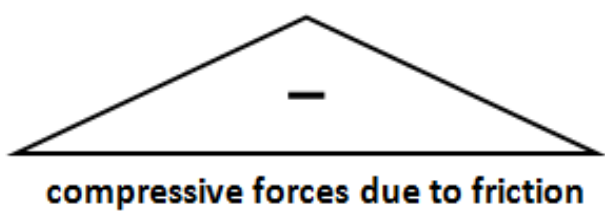

(a) Expansion asymmetric phenomenon. More specifically, contraction due to concrete drying (from $0.02 \%$ to $0.04 \%$, giving an equivalent temperature reduction from $20{ }^{\circ} \mathrm{C}$ to $40{ }^{\circ} \mathrm{C}$ ) combined with contraction due to temperature reduction, results in a restraint load much greater than this of temperature increase. Moreover, if the $\mathrm{EC} 1$ values $\pm 25{ }^{\circ} \mathrm{C}$ for temperature changes are considered, it is apparent that the temperature increase's influence is eliminated by the equivalent contraction due to drying. At the same time, the combination of the latter with the thermal contraction creates an equivalent contraction which corresponds to a $50{ }^{\circ} \mathrm{C}$ to $60{ }^{\circ} \mathrm{C}$ temperature reduction.

\subsubsection{Uneven Temperature Changes}

Temperature increase on the top surface of the slab accompanied by its delay in reaching the bottom surface, results in slab curling, as shown in Fig. 3.

In order to calculate the curling stresses in ground slabs, a temperature gradient $\Delta t$ is initiated. $\Delta t$ reaches a value of approximately $5{ }^{\circ} \mathrm{C}$ at indoor slabs. This temperature difference between the top and bottom surface of the slab generates curling in its middle area. In response to this curling, self weight loads activate flexural stresses on the bottom side of the slab which are regarded as curling stresses. When the slab to be designed has theoretically infinite length, its shape of deformation is similar to this of a clamped slab on two or all four sides $[3,6]$.

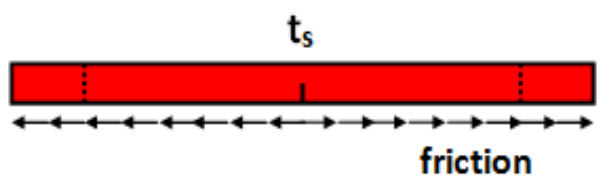

tensile forces due to friction

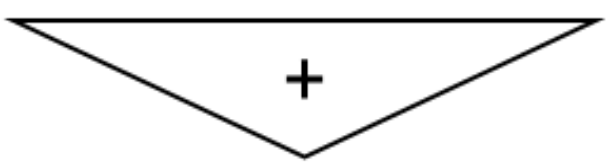

(b) Contraction

Fig. 2 Forces developed at the slab with temperature changes. 


\section{TOP SURFACE}

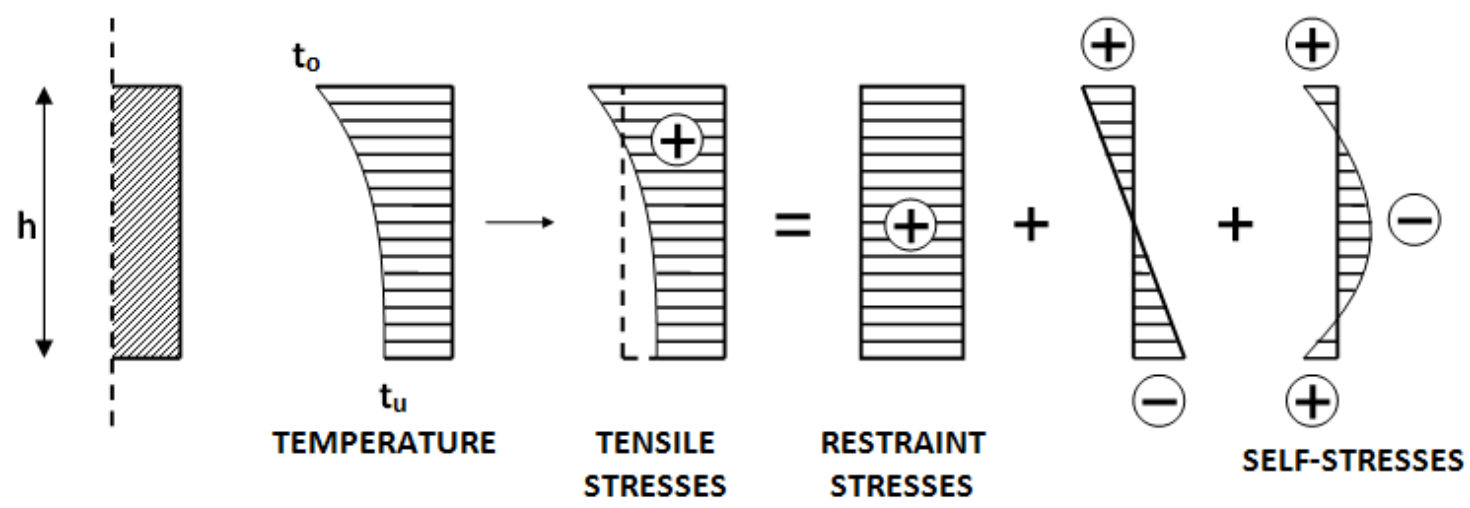

(a)

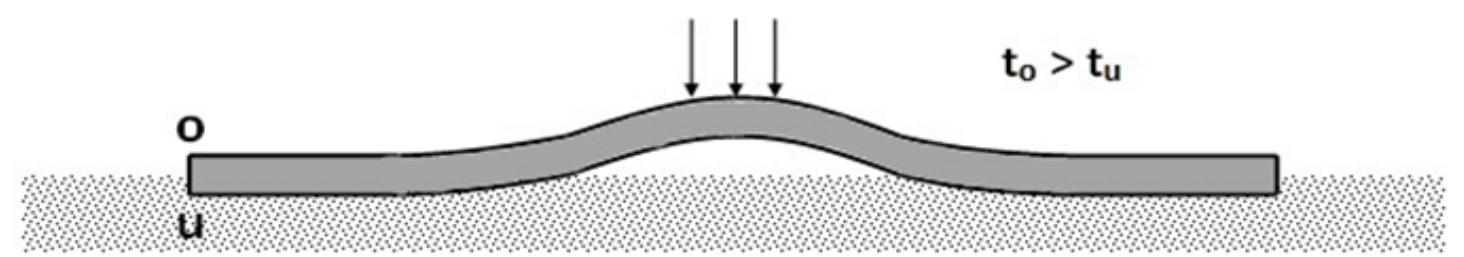

(b)

Fig. 3 (a) Temperature distribution across the slab; (b) slab curling.

\section{Description of the Jointless Solution}

\subsection{Introductory Elements}

In order to design a ground slab, several requirements should be taken into consideration. Namely, the type of load applied (static loads, restraints), the desirable working life and soil conditions. Ground slabs require high quality concrete for the following reasons: (1) The high strength that characterizes high quality concrete, permits the reduction of slab thickness and that fact has beneficial effects on the elimination of the $\Delta t$ restraint and on the better behavior regarding differential settlements, since the moment of inertia is drastically decreased and the modulus of elasticity remains more or less the same; (2) It is known that the impacts of contraction due to drying and creep weaken on high quality concretes; (3) By reducing slab thickness, self weight reduces as well and as a result, friction between the slab and the subbase lowers; (4) In the case that the slab is reinforced conventionally or with steel fibers, the controlled transition from uncracked to cracked phase (in terms of acceptable crack width) requires lower steel per concrete ratio, by virtue of concrete strength.

The issue of ground slabs reinforcement went through many phases before settling on steel fiber at low percentage of reinforcing steel $\left(25 \mathrm{~kg} / \mathrm{m}^{3}\right)$. The main purpose of this solution is to enhance concrete ductility rather than to increase its tensile strength, to which steel fiber reinforcement little has to offer. Additionally, it would be unwise to increase steel reinforcement, since concrete workability would be impaired and its placement time would be unprofitably elongated with few positive results on its strength. However, steel fiber reinforcement has two advantages. Firstly, the construction time is shortened and secondly, it does not influence the electromagnetic field that automated vehicles need to operate. In contrast, conventional reinforcement does affect the electromagnetic field and for that reason, is placed below the zone that concrete coverage requirements dictate. As a result, the static height of 
the reinforced slab shortens [8].

\subsection{Philosophy of Recommended Solution}

The description of the proposed jointless solution for indoor ground slabs are given in the following.

Concerning the joints, only the isolation joints of vertical bearing elements are included in this solution, either being within the slab plan or on its perimeter. Around the perimeter of the slab, two construction methods could be applied.

In the first method, slab boundaries are not connected to the foundation walls which enclose the slab foundation (subbase and subgrade). In the second method, slab boundaries are monolithically connected to the foundation walls which partially impede the slab deformation towards the center of its plan. The upper edge of the foundation wall is subjected to a restraint load which must be taken into account. So measures should be taken to confront this problem. One of these measures could be the improvement of passive forces resulting from the subbase and subgrade (which constitute the slab foundation) resistance to the inward movement of the foundation wall. Another measure (that mostly helps the structural system to adapt to the problem rather than to solve it), is the expansion of the foundation wall footing in order to prevent high rotational movements. The thickness and reinforcement of the foundation wall in its base should be calculated regarding the aforementioned restraint load. The increase in passive forces of slab foundation could be achieved by impregnating the graded crushed aggregates with a cement mixture within a zone of $1 \mathrm{~m}$ width.

It is obvious that the method described in the beginning permits free movement of the slab with the exception of friction forces which oppose that movement. Friction forces are limited due to the low thickness, hence the low self weight of the slab, despite the increased value of the friction factor which varies from 1.5 to 1.8 . In the second method, slab movement is impeded and friction forces are very low, provided that the deflection of the upper edge of the foundation wall is practically zero.

In the case of jointless slabs, their minimum thickness which is approximately $150 \mathrm{~mm}$ suffices to accommodate all requirements. The reason is that in jointed slabs, the maximum tensional stress when the load is applied to their perimeter is almost twice the value of the tensional stress when the load is applied to the middle area. The minimum thickness is estimated with regard to minimum concrete covers and the requirement of fitting two grid reinforcements inside the slab. Apart from the absence of joints, high quality concrete contributes significantly to the adequacy of slabs load bearing capacity. Another reason leading to smaller slab thickness, is the minimization of reinforcement against restraints, which is expressed as a percentage of slab section area.

It is no exaggeration to say that the combination of high quality concrete, the absence of joints and the minimum slab thickness $(15 \mathrm{~cm})$ ensures a reliable load bearing capacity to uncracked concrete and without the reinforcement's contribution. However, absence of joints implies restraint forces which provoke tensional and flexural stresses which will definitely result in cracking. This crack width could be limited by grid reinforcement which is calculated by the following formula:

$$
A_{s}=k \cdot f_{c t m} \cdot \frac{A_{c t}}{\sigma_{s}}
$$

where,

$A_{c t}$ is the tension zone of uncracked concrete;

$f_{c t m}$ is the average tensile concrete strength;

$k$ is the coefficient determined considering the stress condition of the structural element, for pure tension and rectangular section $k$ values depend on the thickness of the structural element according to Fig. 4;

$\sigma_{s}$ is the reinforcement tension (cracked concrete), determined considering the selected diameter and the maximum tolerable crack width which is equal to 0.3 $\mathrm{mm}$ or $0.2 \mathrm{~mm}$. 


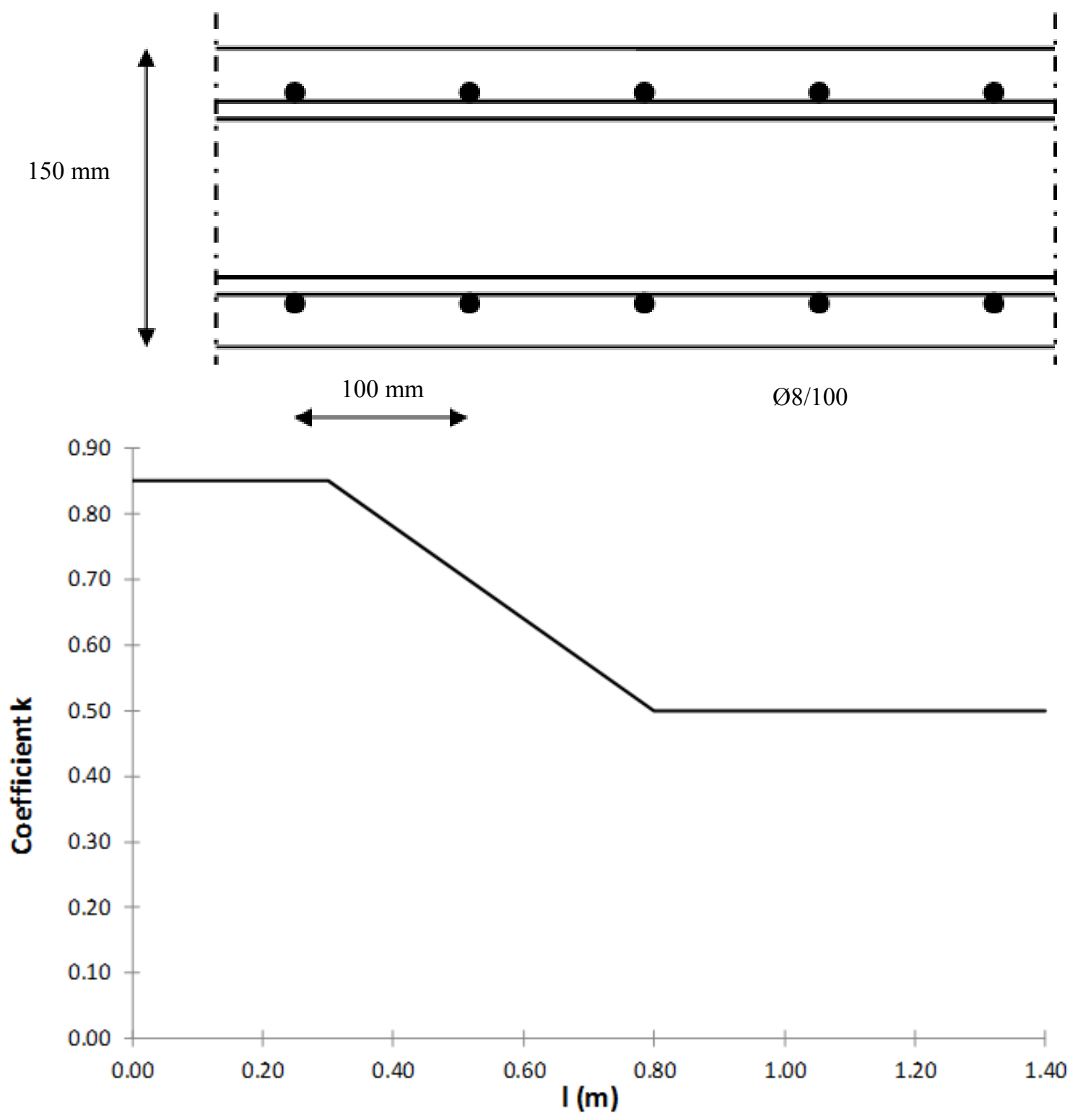

Fig. $4 k$ coefficient values for pure tension.

Based on this formula, the reinforcement percentage in both directions equals to $\rho=0.85 \times$ $2.9 / 350=0.007$.

Consequently, the per meter steel reinforcement area is $A_{s}=0.007 \times 15 \times 100=10.5 \rightarrow 2 \varnothing 8 / 100 \mathrm{~mm}$ (meaning that one bar is placed in the top and the other in the bottom of the slab).

Fig. 5 shows the response of ground slab during winter, in terms of applied force vs. width of developed cracks. In the ground slab under tension, the stresses of the longitudinal reinforcement equilibrate the tensile stresses that are developed in the element.

Fig. 6 presents the idealized behavior of a reinforced concrete tie. According to this figure, the contribution of the concrete may be considered to increase the stiffness of the tensile reinforcement (tension stiffening effect).

Fig. 7a shows the distribution of strains after the appearance of the first crack, while Fig. $7 \mathrm{~b}$ depicts the distribution of strains after the element has been fully cracked. In the areas between cracks, the tensile forces 


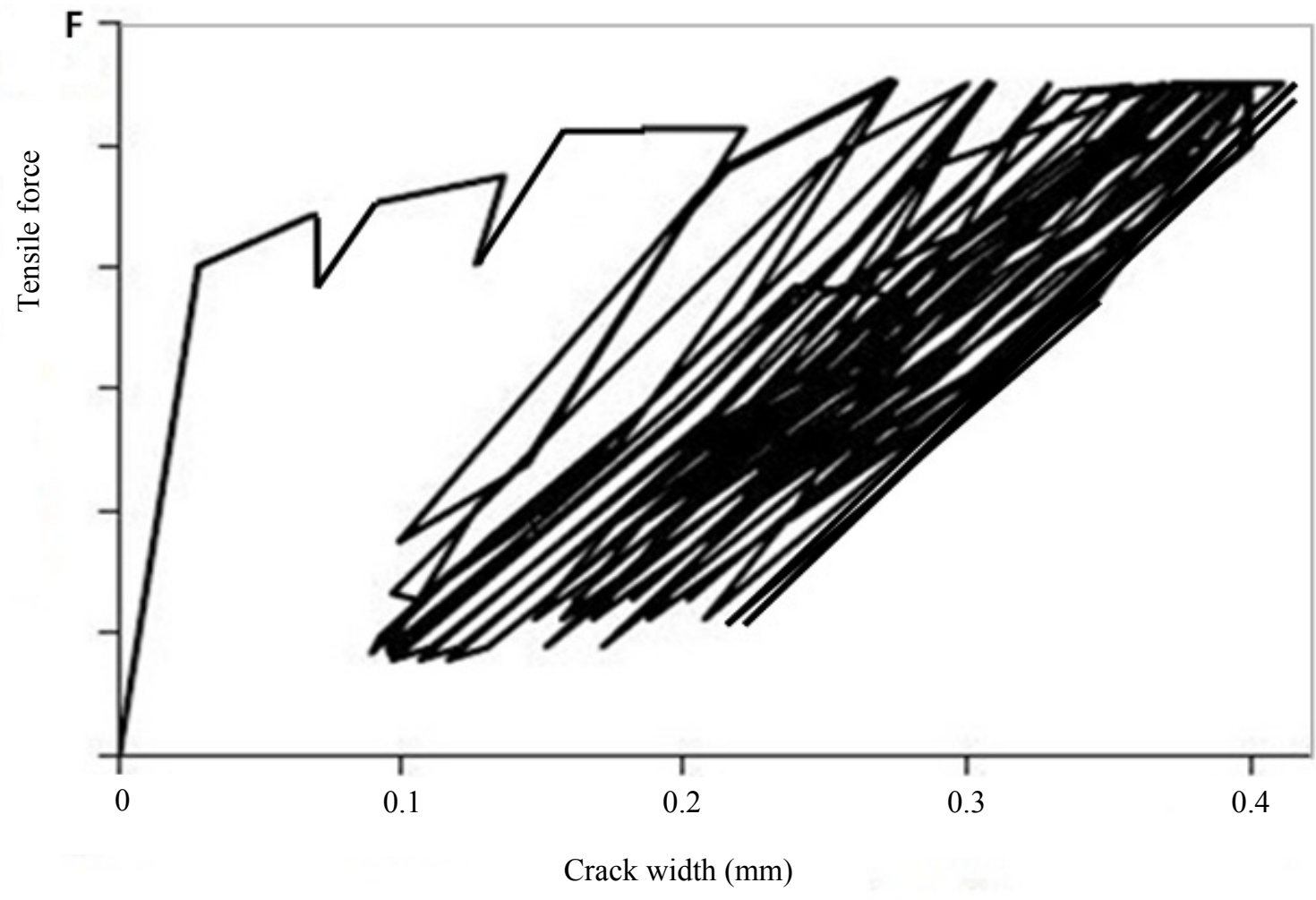

Fig. 5 The response of slabs under changing tension.

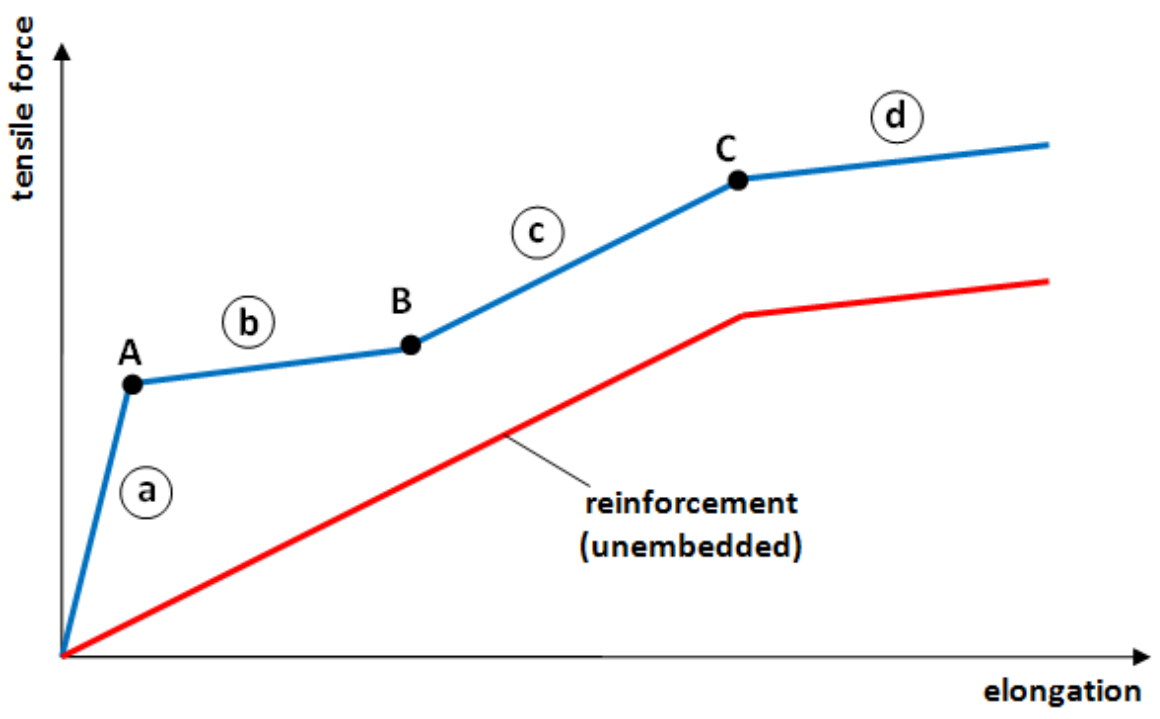

a) uncracked

b) crack formation

c) stabilized cracking

d) post yielding

A: first crack

B: last crack

C: yielding

Fig. 6 The idealized behavior of a concrete tie.

are transferred from steel to concrete by the friction (bonding) forces. Concrete contributes to reinforcement's axial stiffness increase. The aim is to reduce the width of the cracks induced and to keep them within acceptable limits according to the Eurocode 2-Part 1 (2004).
The restraint load per meter, in the extreme scenario of immovable top edge of the foundation wall, is calculated as follows: $F_{s}=A_{s} \times \sigma_{s}=10 \times 35=350 \mathrm{kN}$. It is important to outline that the limited rigidity of the foundation wall contributes drastically in decreasing the restraints of the slab, since its movements are not 


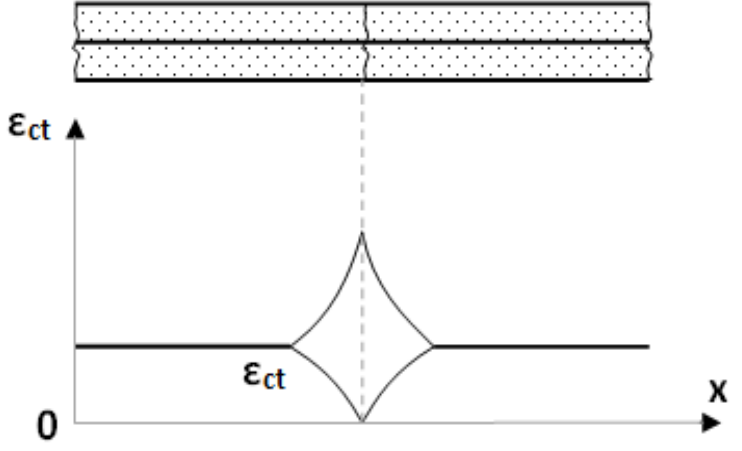

(a) Single crack

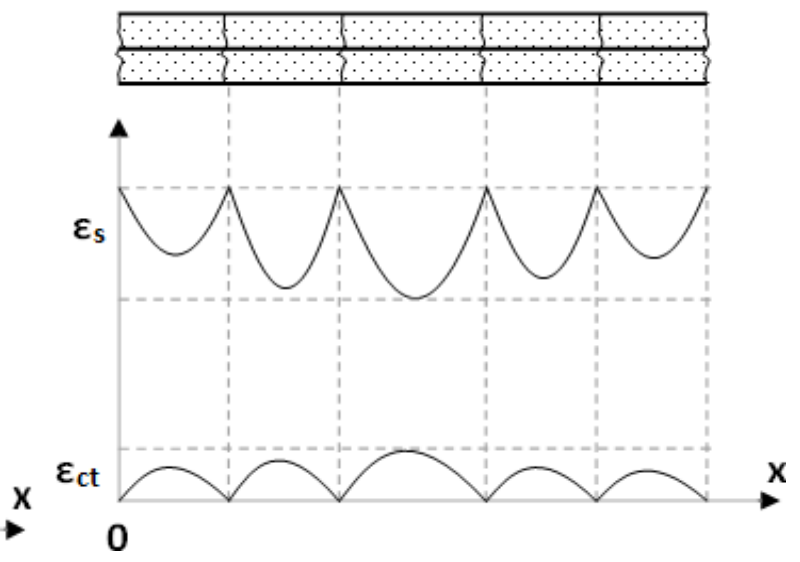

(b) Final stage

Fig. 7 (a) The distribution of strains after the appearance of the first crack; (b) the distribution of strains after the element has been fully cracked.

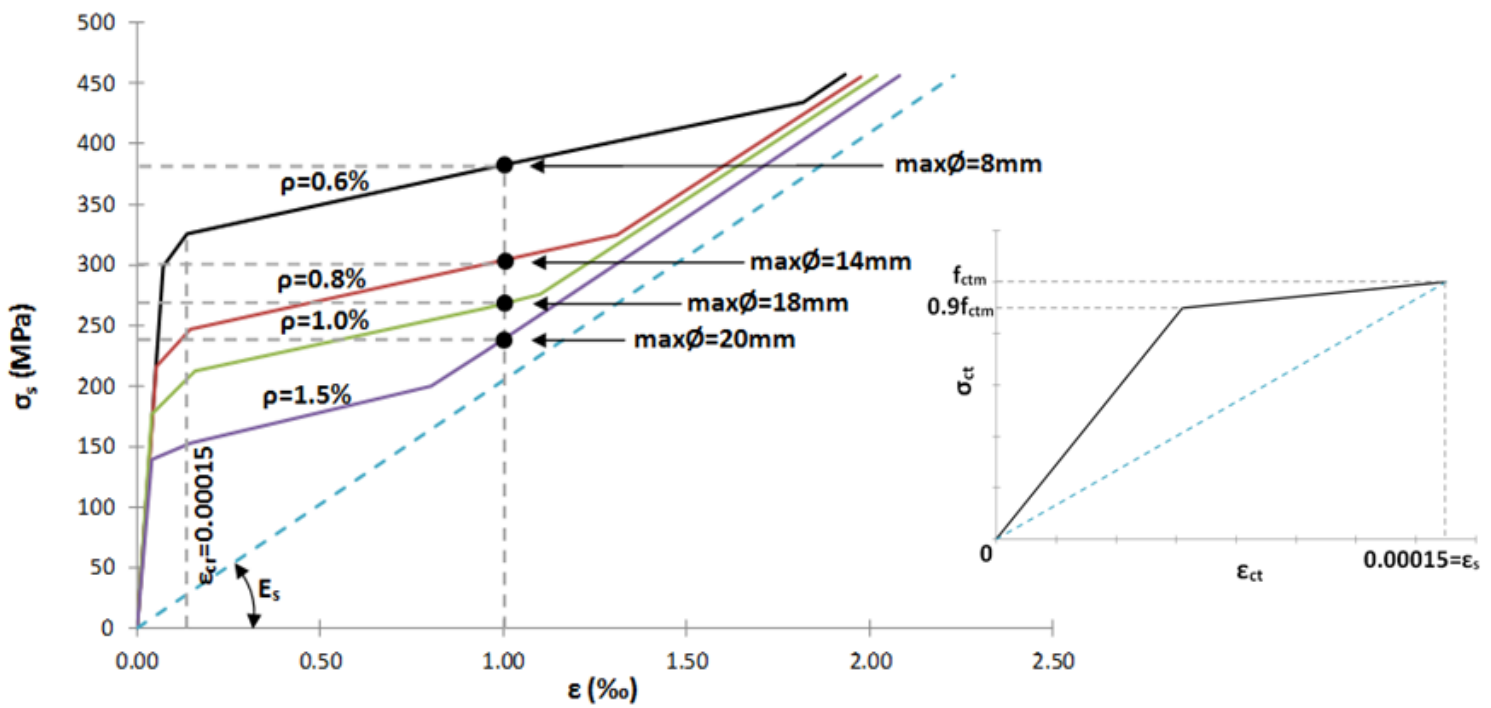

Fig. 8 Stress-strain diagrams of ties for several reinforcement percentages.

totally hindered. The response of slabs subjected to restraints, is displayed in Fig. 8. According to Fig. 8, after the uncracked phase of the slab (until a strain of $0.015 \%$ which initiates cracking), the cracked phase follows during which reinforcement's tension remains almost stable up to a strain limit and eventually the restraint load does not increase. It is implied that due to the hindrance of slab contractions, its behavior resembles that of a reinforced concrete tie rod. In the case that the combination of temperature reduction and drying contraction (which is regarded as equivalent to a temperature reduction of $30{ }^{\circ} \mathrm{C}$ because of high quality concrete) is considered as the critical restraint load, then the total temperature reduction would be $T=30{ }^{\circ} \mathrm{C}+25{ }^{\circ} \mathrm{C}=55{ }^{\circ} \mathrm{C}$, resulting in a strain of $\varepsilon=\alpha_{t} \times T=10^{-5} \times 55=0.00055$. According to Fig. 8, the strain value lies within the sawblade-like section of the diagram, meaning that the stresses of the slab reinforcement will not reach the maximum tolerable value of $\sigma_{s}=350 \mathrm{MPa}$. That being said, the crack width will be lower than the acceptable value. Moreover, the restraint load, which has been estimated equal to $350 \mathrm{kN}$, is actually smaller because of reinforcement stress reduction. Fig. 8 displays the stress-strain diagrams of ties for several reinforcement percentages $[9,10]$. 
Creep effect is an additional factor that increases significantly the movements at the top edge of the foundation wall. Creep introduces a lasting force which probably contributes to the most part of the foundation wall deflection. As mentioned before, this deflection permits the stress relief of the slab from restraints.

Fatigue is the Achilles' heel of unreinforced jointed slabs, whose durability becomes extremely low due to this fact. The recommended solution burdens the reinforcement with this problem, so slabs employing this solution hold a considerable advantage over fatigue.

The aforementioned curling issue and generally the elevational displacements of a slab, which does not have the relieving effects of joints, constitute a problem not to be ignored. However, in this particular instance, there are two favorable facts: The first is the small thickness of the slab and the second the favorable indoor conditions. Furthermore, reinforcement confronts the combination of stresses due to curling and those due to gravity loads effectively, in comparison with unreinforced slabs. Nevertheless, the present work recommends a mechanism which restrains the transverse displacements of the slab, at the intersection points of a rectangular grid whose size varies from $5 \mathrm{~m} \times 5 \mathrm{~m}$ to $7 \mathrm{~m} \times 7 \mathrm{~m}$. It is essential to clarify that the slab plane is parallel to the grid plane. In the following paragraph, a typical restraining point is described.

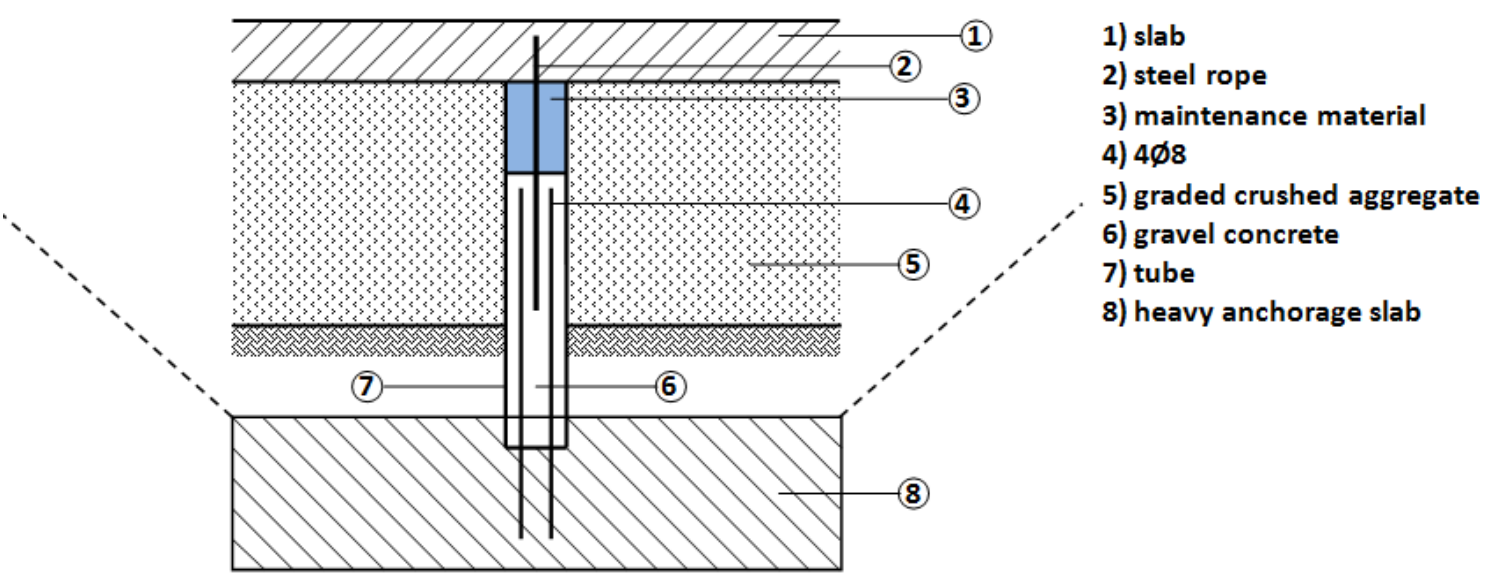

Fig. 9 Curling prevention mechanism.

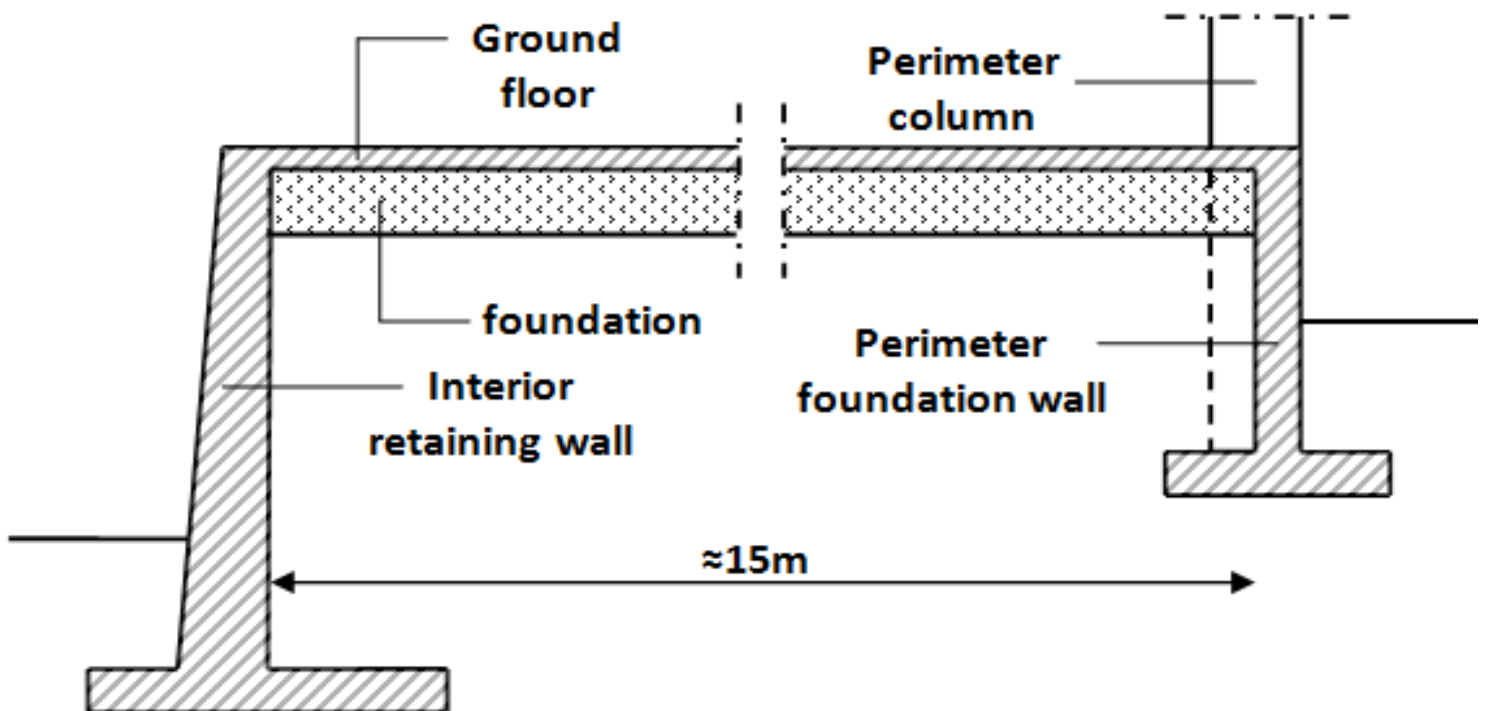

Fig. 10 Jointless slab which connects the interior retaining wall with the perimeter foundation wall. 
Before the layers under the slab are compressed, a special "foundation-slab" measuring $1 \mathrm{~m} \times 1 \mathrm{~m}$ area and $30 \mathrm{~cm}$ thickness is concreted and slightly reinforced with a grid at its top surface. To the center of the foundation-slabs, a plastic or stainless tube is clamped which extends almost up to the lower level of the slab. The diameter of the tube could be of the order of $10-15 \mathrm{~cm}$ and its interior is partially filled with concrete, clamped to the foundation-slab via slim reinforcement bars. A 6/10-inch steel rope is embedded in the tube's concrete and its upper end is to be anchored in the slab. The installation of this mechanism is followed by the compression of the supporting layers of the slab and its concreting. The steel rope resistance to the vertical displacements of the slab is assisted by the weight of the layers lying between the slab and the foundation-slab. Toward this end, the reason using steel rope instead of conventional reinforcement bar, is that the first can easily accommodate the displacements (due to expansions and contractions) parallel to the slab plane, in contradiction to the latter which no matter how slim or flexible is, cannot meet the requirements. Fig. 9 displays this mechanism.

\section{Application}

The procedures described before were tested in one of the warehouses of the supermarket chain "MASOUTIS" located in Thessaloniki. The technique was applied to a part of the warehouse slab $(15 \mathrm{~m} \times$ $120 \mathrm{~m}$ area) which bears stored material loads and material handling equipment loads. The slab in question is located inside the warehouse and connects the top edge of the interior retaining wall with the top edge of the foundation wall of the elevated floor. This connection is intended to support the retaining wall which was designed as supported at both ends (the one end fixed, the other simply supported) and not as cantilever. After two years, no cracking has occurred in the slab which absolutely meets all serviceability demands. Fig. 10 shows the method of application.

\section{Conclusions}

Recent years have shown that conditions for complete suppression of joints in large length and area constructions are now mature. Inspired by this fact, the authors of this paper present a solution for ground slabs that takes us one step forward concerning the monolithicity of these sensitive structures for which joints imply many problems. Finally the following conclusions are summarized.

The recommended solution constitutes a global approach to the problem, since it provides measures for all possible strains and especially those deriving from restraints.

The recommended solution could be characterized as economical in terms of concrete consumption, as the slab thickness is significantly reduced.

As for the construction time, the present proposition loses the edge due to the time consuming reinforcement placement, however it does not employ dowels and joints which also require time for their proper application.

The present proposition prevails in terms of maintenance cost which is diminished.

The recommended structure holds a considerable advantage against fatigue and lasts longer than the jointed one.

A large-scale application, which could be considered as experimental confirmation, is proved successful after the lapse of two years from the construction date.

\section{References}

[1] E.K. Schrader, A solution to cracking and stresses caused by dowels and tie bars, ACI Concrete International 13 (7) (2001) 40-45.

[2] ACI Committee 360, ACI 360R-06, Design of Slabs-on-Ground, Farmington Hills, MI, 2004.

[3] European Committee for Standardization, EN 1991-5:2003, Eurocode 1: Actions on Structures-Part 1-5: General Actions-Thermal Actions, Brussels, Belgium, 2003.

[4] European Committee for Standardization, EN 1992-1:2004, Eurocode 2: Design of Concrete 
Structures-Part 1: General Rules and Rules for Buildings, Brussels, Belgium, 2004.

[5] European Committee for Standardization, EN 1992-1:2004, Eurocode 2: Design of Concrete Structures_Part 2: Bridges, Brussels, Belgium, 2004.

[6] I.A. Tegos, N.C. Giannakas, Slabs on soil: The known-unknown concrete structural elements, in: 15th Greek Concrete Conference, Alexandroupoli, Greece, Oct. 18-20, 2006, pp. 495-509.

[7] Concrete Industrial Ground Floors-A Guide to Design and Construction, 3rd ed., Concrete Society Technical report No. 34, 2003.
[8] S.A. Kolias, S.B. Tsoukantas, G.G. Kremmyda, T.D. Topintzis, Design of concrete ground floors, in: 16th Greek Concrete Conference, Pafos, Cyprus, Greece, Oct. 21-23, 2009.

[9] The International Federation for Structural Concrete (fib-fédération internationale du béton), Model Code 1990, Final Draft, CEB Bulletin No. 204, 1991.

[10] I.A. Tegos, S.D. Tegou, V.P. Panoskaltsis, M. Tsitotas, Reduction in seismic actions of bridges by utilizing the sidewalks as restrainers, in: 15th World Conference on Earthquake Engineering (15th WCEE 2012), Lisboa, Portugal, Sep. 24-28, 2012. 